\section{From the Principal Editor}

A number of changes to the infrastructure of Mineralogical Magazine have taken place over the summer. In June I took over from Prof. Simon Redfern as Principal Editor, and I would like to take this opportunity, on behalf of the Mineralogical Society, to thank him for his valuable contribution over the past six years at the helm of the journal and to thank Xiaojie Lou, editorial assistant, who played an important part in the management of the journal, not least in the transitional hand-over period during the summer. From now on, please submit all manuscripts to minmag@nhm.ac.uk

We welcome to the editorial board Prof. Edward Grew (University of Maine, USA), Dr Fernando Cámara (University of Pavia, Italy) and Dr Diego Gatta (University of Milan, Italy). Dr Cámara will take over from me as Crystal Structures Editor and be directly responsible for handling and data-checking crystallographic manuscripts (see below).

\section{On-line submission and manuscript tracking}

A major change for the journal will take place in the autumn with the installation of an on-line manuscript submission and tracking system (Allentrack) that will be the default mode for dealing with future manuscripts. This system allows authors to keep an eye on the progress of their manuscript through review and revision, giving greater transparency than has been available. It should also reduce the administrative burden on the editorial team. While still welcoming hard copy submissions, authors will be encouraged to submit their manuscripts online. Allentrack is an intuitive system that has a proven track-record with American Mineralogist and many other journals. Instructions on the procedure for accessing Allentrack will be given in the October issue of the journal.

\section{Crystallographic manuscripts: CIF validation and deposited material}

In order to bring Mineralogical Magazine into line with standard practices in the validation of crystallographic data (cf. Acta Crystallographica $C$ ), a new requirement for submission of a paper describing the crystal structure of a new mineral species is that the authors submit a Crystallographic Information File (.cif) that will be routinely checked by the Crystal Structures Editor using the cif-validation programme PLATON written by Ton Spek (www.cryst.chem.uu.nl/platon/). The Crystal Structures Editor will then alert the authors to any significant anomalies in the dataset before the manuscript is sent out for review. We also request that all authors submit their structure-factor tables in the standard .sft file format for electronic deposition. We encourage authors to visit the PLATON website if they are not already using this programme for structure validation.

\section{Colour figures}

Finally, just to remind all authors that Mineralogical Magazine will publish figures in colour free of charge if they are deemed essential or highly desirable. Those authors submitting crystal-structure papers are encouraged to prepare high-quality colour structure figures in the expectation that these will be published in colour. The final decision regarding publication of colour figures lies with the Principal Editor who will be very happy to discuss the use of colour with authors.

MARK WeLCH Department of Mineralogy The Natural History Museum London 